\title{
Geospatial Analysis of Urban Sprawl Patterns in Amritsar City, Punjab, India
}

\author{
Minakshi \\ Scientist \\ Punjab Remote Sensing \\ Centre PAU Campus, \\ Ludhiana, India
}

\author{
Shivani Singh \\ Research Associate \\ Punjab Remote Sensing \\ Centre PAU Campus, \\ Ludhiana, India
}

\author{
Brijendra Pateriya \\ Director \\ Punjab Remote Sensing \\ Centre PAU Campus, \\ Ludhiana, India
}

\begin{abstract}
Amritsar is the largest and most important city in northern Punjab. Amritsar serves as a major commercial, cultural, and transportation hub with Golden Temple \& Raja Sansi international airport. It lies about $25 \mathrm{~km}$ east of the border with Pakistan and gateway for travelers coming to India on the overland route from central Asia. The present study attempts to understand, detect and quantify the spatial pattern of Amritsar urban sprawl using Shannon's entropy and multitemporal satellite images acquired for the period from 1972 to 2015. Shannon's entropy has been used to model the city's urban sprawl, trend and spatial change. The entropy values for the different grids were modeled and the interpolation function in ArcGIS is used to obtain an entropy surface for each acquired temporal image. The entropy surface index indicates the spatial pattern of the urban sprawl and facilitates to visual assess the entropy phenomenon in all the grids. The value of Shannon's entropy index increased from (0.40) in year 1972 to (0.97) in year 2015, indicating more dispersed urban growth, an indication of urban sprawl. Results obtained from entropy indices help in understanding the sprawl patterns and dynamics among different grids and provide a visual comparison which facilitates the decision makers and city planners for measuring the urban sprawl required for mega cities.
\end{abstract}

\section{General Terms}

Urban Sprawl, Shannon's Entropy.

\section{Keywords}

Shannon's Entropy, Urban Growth, Sprawl Patterns, Remote Sensing \& GIS

\section{INTRODUCTION}

Understanding of the growth dynamics of urban agglomerations is essential for ecologically feasible developmental planning. With almost one third of India's population already residing in urban centers, it is necessary to study the growth patterns of cities and its impact on the living environment. The current trend of spatial urban growth in most of the Indian cities is haphazard and in an unplanned manner, particularly along the urban-rural fringes. There is an obvious need for continuously monitoring the phenomena of growth of cities/ towns, and mapping and analyzing the growth patterns. However, there are many techniques which are dedicated to measure \& monitor the urban sprawl characteristics manually \& automatically (Yeh and Li, 2001; Theobald, 2001; Barnes et al., 2001; Sudhira et al., 2004; Wei et al., 2006; Yu and Ng, 2006; Singh, 2014; Hala et al., 2015). However most of these studies have come up with different methodologies in quantifying sprawl. Shannon's entropy is specially designed to measure the sprawl within the integration of Remote Sensing \& GIS and these can be used as useful tools to study the urban sprawl as it decrease the cost of data generation and also save time. Mapping urban growth by conventional methods is too tedious and a slow process, and by the time information becomes available to planners, it is already outdated and redundant since the damage has already been done. In the recent years a lot of thrust in this field has been used to understand and analyze the urban sprawl pattern.

Satellite remote sensing data and application of GIS technologies provide an alternative means of rapidly assessing the dynamics and development of sprawl so that timely action may be taken. Besides being flexible and extensible, the datasets are easily rectified, updated and may be used for other applications. The high resolution satellite imagery offers new possibilities for the assessment distinctly gives better results for identification of features than the data sets of medium resolution and gives crisper boundaries of polygon features which make their delineation more accurate. Additionally, high resolution imagery has been found extremely suitable for identification and delineation of linear features such as road network, especially forest roads more accurately. Punjab is known as food grain basket of India and economy of the state depends on the agriculture hence it is very much required to check the conversion of fertile agriculture land for other non-agricultural activities especially at the fringes of the boundaries of settlements.

\section{STUDY AREA}

Amritsar is one of the most ancient and fascinating cities of India and an important seat of Sikh history and culture. The main objective of the current study is to examine the dynamic phenomenon of urban sprawl/growth and pattern in the highly populated city of Amritsar. The findings may help in studying some of the motivations and spatial patterns of the urban growth in Amritsar. The steps followed to cover the main objectives includes: Mapping land use-land cover changes using satellite imageries to measure the urban growth. The Shannon's entropy model is used to quantify the urban sprawl in Amritsar city. The entropy index has been derived to compare urban sprawl in the various grids.

The study area shown in Figure: 1 decided keeping in view the local planning area map of Amritsar city. Amritsar is located in Punjab state of India between $31^{\circ} 37 ' 59.16^{\prime \prime} \mathrm{N}$ $74^{\circ} 51^{\prime} 56.16^{\prime \prime}$ E latitudes. The study area covers $486 \mathrm{sq}$. km. of area including 87 villages in full and parts of another 26 villages surrounding the Amritsar city. The study area is divided into 14 grids ( $5^{\prime}$ by $\left.5^{\prime}\right)$ to calculate the entropy value. 


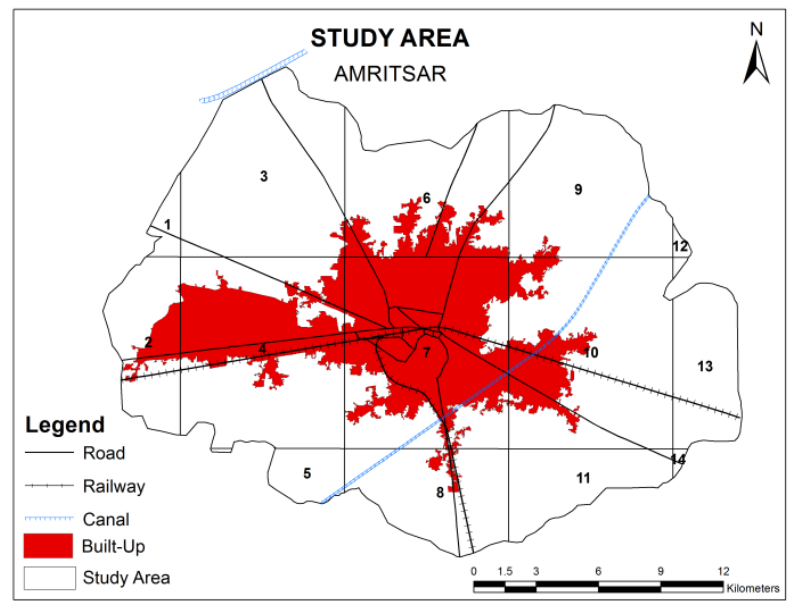

Fig 1: Study Area.

\section{MATERIAL AND METHODOLOGY}

The Topographical sheet of 1972 is used as a reference to perform four times satellite data. The various satellite data sets are used to drive the multi series urban area extents for the four different years i.e. 2002, 2006, $2010 \& 2015$. The maps generated for different years are overlaid in Arc GIS to map the urban sprawl and land transformation from agriculture to build up. The area statistics of built up land within the study area for these years were calculated.

The study area is marked using the local planning area map of Amritsar city. Base map of the study area showing permanent features like road, railway and canal were prepared. Periodical mapping of the urban area is carried out for the years 1972 (topographical sheet), 2002 (LISS III), 2006 (Cartosat-1), 2010 (LISS IV+ CartoSat PAN merged) \& 2015 (Google) satellite data through on-screen visual interpretation in GIS environment using standard methodology. The methodology followed has been depicted in Fig 2 .

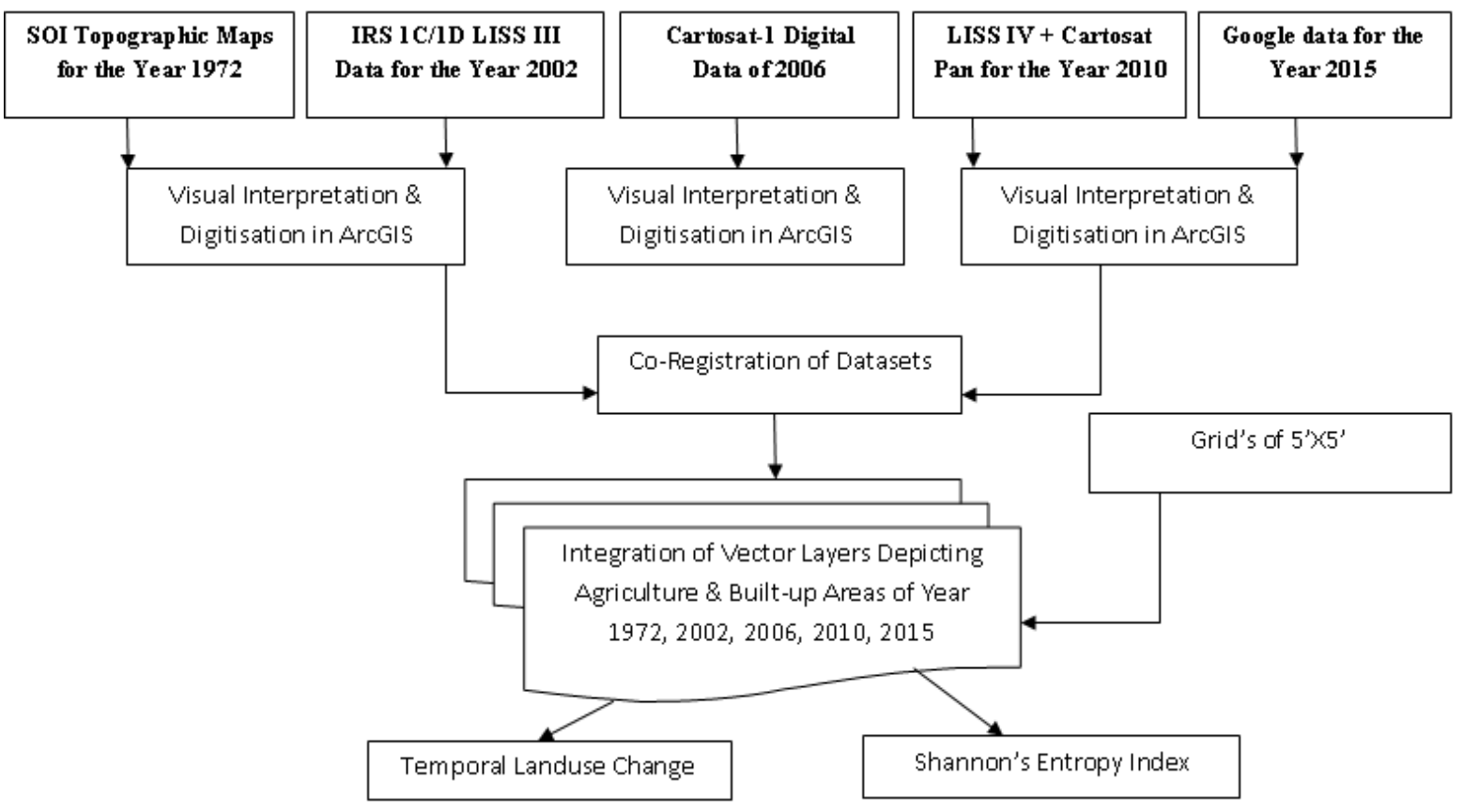

Fig 2: Methodology Flow Chart

\section{RESULTS AND DISCUSSION 4.1 Mapping of Land Transformation in Amritsar city}

Urban sprawl refers to the expansion of town or city as a result of natural population and influx of migrants due to industrial or commercial purpose. Physical growth of Amritsar city from the year 1972 to 2015 has been studied with the help of survey of India topographic maps (1972) and multi date remote sensing data viz. IRS IC/ID LISS III March 2002, Cartosat data of 2006, LISS IV + Cartosat Pan for the Year 2010 and Google image of 2015 employing both visual and digital technology and supported by ground check. Land use maps of Amritsar (Fig: 3 to Fig: 8) were prepared for the years 1972, 2002, 2006, 2010 and 2015 using the ARC-INFO GIS software. In 1972 (Fig: 3), the urban area of Amritsar consists of old, thickly populated core constituting the ancient city confined mostly with in the double wall prepared at the time of Maharaja Ranjit Singh.
This core area is almost completely covered and there appears to be no patch available for any kind of development. Amritsar's central walled city has narrow streets mostly developed in the 17th and 18th century. The city is a peculiar example of an introverted planning system with unique areas called Katras. The Katras are self-styled residential units that provided unique defence system during attacks on the city. To the south east of Amritsar railway station is the dusty and congested old city crowded with narrow zigzag streets with mixed commercial and residential structures. Golden temple is in the heart of the old city and the walls of Maharaja Ranjit Singh time had been demolished to a ring road around the city. The other rural built ups are scattered around the city with in the study area. The area statistics of built up land within the study area for the year 1972 was commuted and amounted to be 53.32 sq.km(Table-1). The IRS-IC/ID LISSIII, March 2002 data was used to map the built up area with in the area of interest for the year 2002 (Fig: 4). 
Table 1: Built up and cultivated area around Amritsar City (1972-2015)

\begin{tabular}{|c|c|c|c|}
\hline Year & $\begin{array}{c}\text { Built up } \\
\text { area (Sq. } \\
\text { km.) }\end{array}$ & $\begin{array}{c}\text { Cultivated area } \\
\text { (Sq. km.) }\end{array}$ & $\begin{array}{c}\text { Increase } \\
\text { in built } \\
\text { up (Sq. } \\
\text { km.) }\end{array}$ \\
\hline 1972 & 53.32 & 432.68 & - \\
\hline 2002 & 127 & 359 & 73.68 \\
\hline 2006 & 142.05 & 343.95 & 15.05 \\
\hline 2010 & 154.17 & 331.83 & 12.12 \\
\hline 2015 & 156.19 & 329.81 & 2.02 \\
\hline
\end{tabular}

The general trend of growth from 1972 to 2002 was observed mainly along the transportation corridors connecting Amritsar-Delhi and Amritsar-Pathankot. The increase in city area through incorporation of surrounding rural areas in the city limits has been a continuing process. However, it could not develop much towards western side due to the proximity of the Indo-Pak border. But after wars in 1965 and 1971, military camps were established in the western side of the city. The new urban areas are being developed to the North East part of the city like Rambagh, Mall and other part area of Amritsar. Part of many surrounding villages were converted into urban built-up in 2002 e.g, Verka, Saidpura, Naushehra, Nangli, Kaler, Kambo, Kala Ghanupur, Gumtala, Mahal, Hair, Bal, Kathanian, Hamidpur, Vadala Guru, Khurmanian, Baser Ke, Guru Wali, Fatehpur, Sultan Wind, Rakh Sukar Garh, Tung Bala, Tung Paian, Miran Kot, Nizarpura and Kot Khalsa. In the year 2002 the total built up land within the study area was calculated to be 127.00 sq.km which amounts to be nearly 2.4 times within a time span of thirty years (19722002). The Carto-sat data of 2006 depicts the pattern of growth which is mainly high density ribbon sprawl towards north western part along Ajnala and Verka roads (Fig: 5) and according to this data the total built up land within the study area comes out to be $142.05 \mathrm{sq}$. $\mathrm{km}$. The growth in the urban area reached 154.17 sq. km for the year 2010 and 156.19 sq. $\mathrm{km}$ for 2015 which shows three times an increase of built up land within span of forty three years. The land transformation towards all the four directions in urban areas has been shown in Fig: 3 to fig: 8.

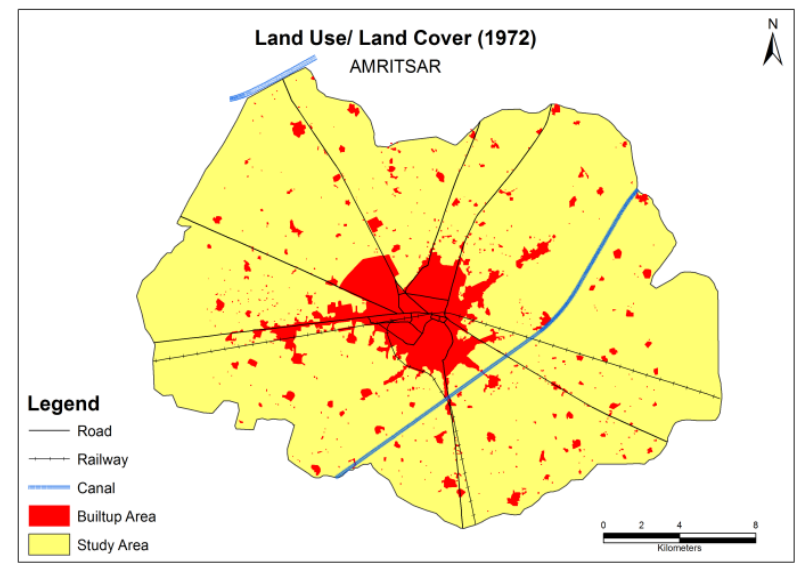

Fig 3: Land Use/Land Cover 1972

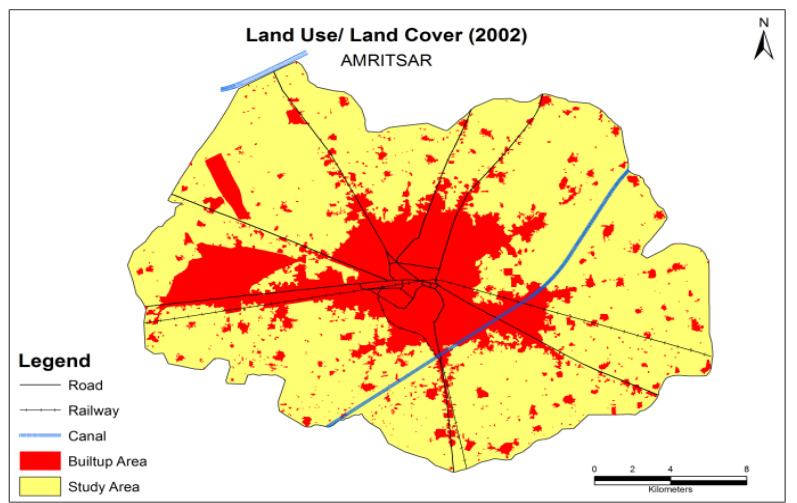

Fig 4: Land Use/Land Cover 2002

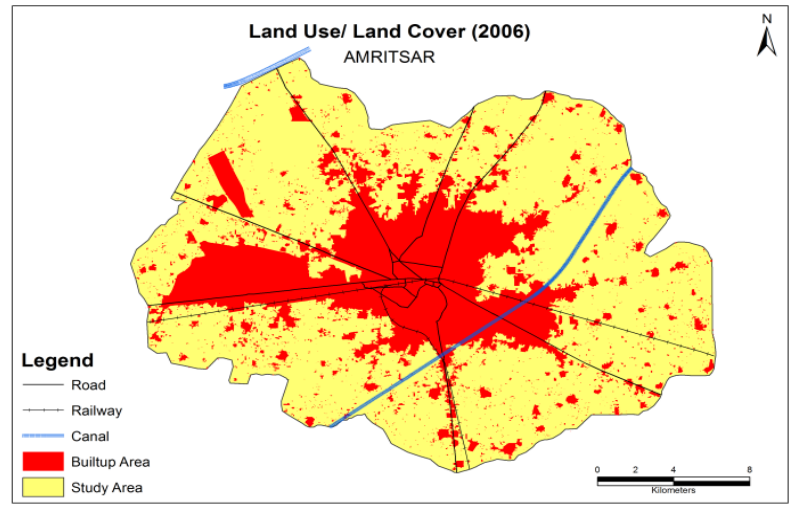

Fig 5: Land Use/Land Cover 2006

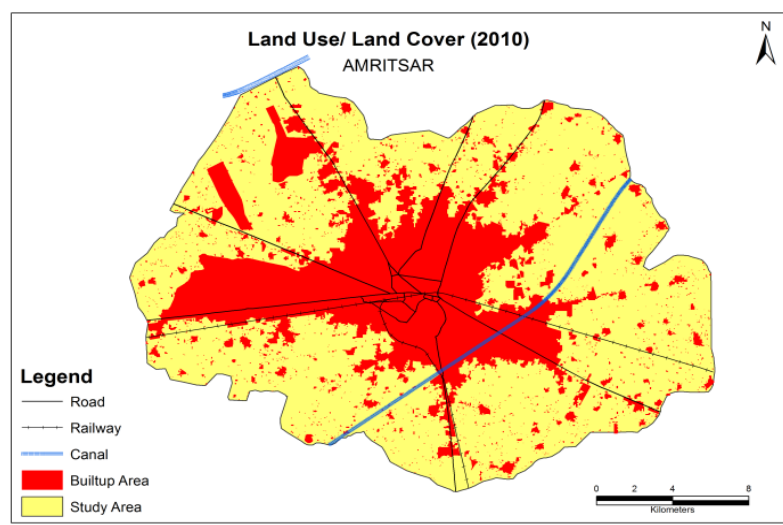

Fig 6: Land Use/Land Cover 2010

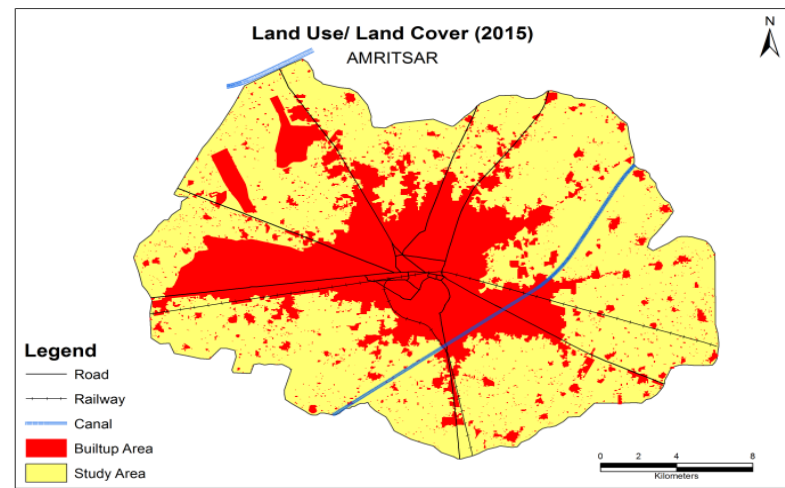

Figure 7: Land Use/Land Cover 2015 


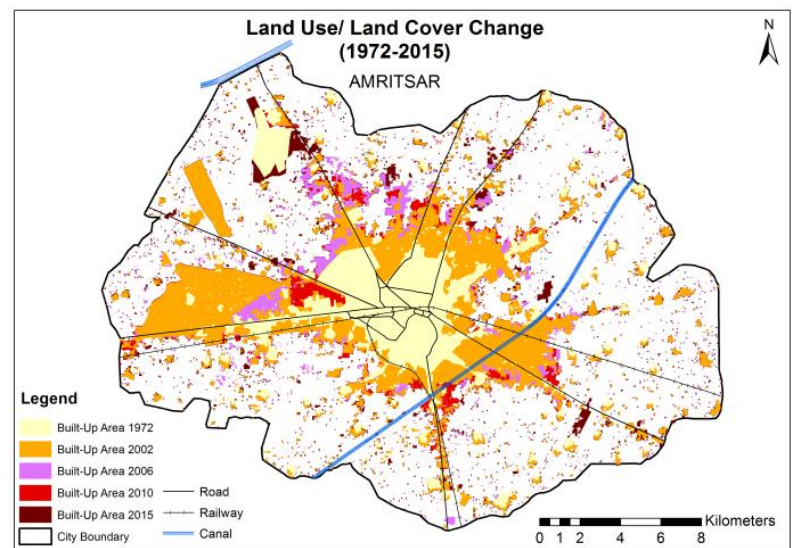

Fig 8: Composite Land Use/Land Cover

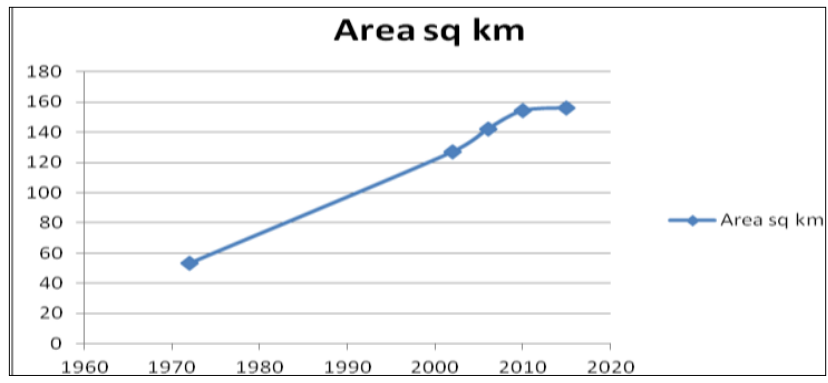

Figure 9: Area Increase trend from 1970 to 2010

\subsection{Calculation of Shannon's Entropy}

For the Amritsar city urban area, Shannon's entropy (Hn) is used to measure the scale of spatial dispersion of built up land among the 14 grids $\left(5^{\prime}\right.$ by 5 '). Shannon's entropy (Yeh and $\mathrm{Li}, 2001)$ has been computed considering the urban sprawl in different grids to detect the form of urban sprawl phenomenon $\&$ patterns. Shannon's entropy $(\mathrm{Hn})$ is given by:

$$
H_{n}=-\sum P_{i} \log _{e}\left(P_{i}\right)
$$

Where $\mathrm{Pi}$ is the proportion of the variable in the $\mathrm{i}^{\text {th }}$ grid, $\mathrm{n}$ is the total number of grids. Pi refers to the built up areas in $\mathrm{i}^{\text {th }}$ grid, $\mathrm{n}$ represents total number of grid (14) and $\log \mathrm{n}$ refers to the upper limit of entropy (2.639). Shannon's entropy has been calculated across all the grids considering each grid as an individual spatial unit (Jat et al., 2008). In the present study, built up area (grid wise) has been considered as the geophysical variable, which enables to determine the urban sprawl. Based on this idea, Shannon's Entropy, when integrated with GIS, has proved to be a simple but efficient approach for the measurement of urban sprawl (Shekhar, 2004; Punia and Singh, 2012). This value ranges from 0 to $\log \mathrm{n}$, indicating very compact distribution for values closer to 0 . The values closer to $\log n$ indicates that the distribution is much dispersed. Larger value of entropy reveals the occurrence of urban sprawl (Sudhira et al., 2004).

Shannon's entropy was calculated for Amritsar city from the built-up area for each grid ( $\mathrm{n}$ is the total number of grids (i.e., $\mathrm{n}=14)$ over different years $(1972,2002,2006,2010$ and 2015) are presented in Table 2 and Table 3.

Table 2: Values of Shannon's Entropy for the study area for in investigated years

\begin{tabular}{|c|c|c|}
\hline S.No & Year & $\begin{array}{c}\text { Shannon'sEntropy } \\
\text { Hn }\end{array}$ \\
\hline 1 & 1972 & 0.39569 \\
\hline 2 & 2002 & 0.81527 \\
\hline 3 & 2006 & 0.89334 \\
\hline 4 & 2010 & 0.95166 \\
\hline 5 & 2015 & 0.96807 \\
\hline \multicolumn{3}{|c|}{$\log n=\mathbf{2 . 6 3 9}$} \\
\hline
\end{tabular}

Entropy value has increased from 0.396 in year 1972 to 0.815 in year 2002. Further, an increase from 0.815 to 0.893 is witnessed in the year 2006 and 0.951 in 2010.But in 2015 there is not much increase in entropy (0.968) as compare to 2010. This increase in value of entropy indicates increase in dispersion of built-up area, which is an indication of urban sprawl. The calculated entropy values are given in Table 4. The closer to the upper limit of $(\log n)$ i.e. 2.369 the more dispersion is the built-up area in the region. Higher value of overall entropy for the whole urban area represents higher dispersion of built up area which is a sign of urban sprawl. Increase in dispersion is due to new areas being added. 


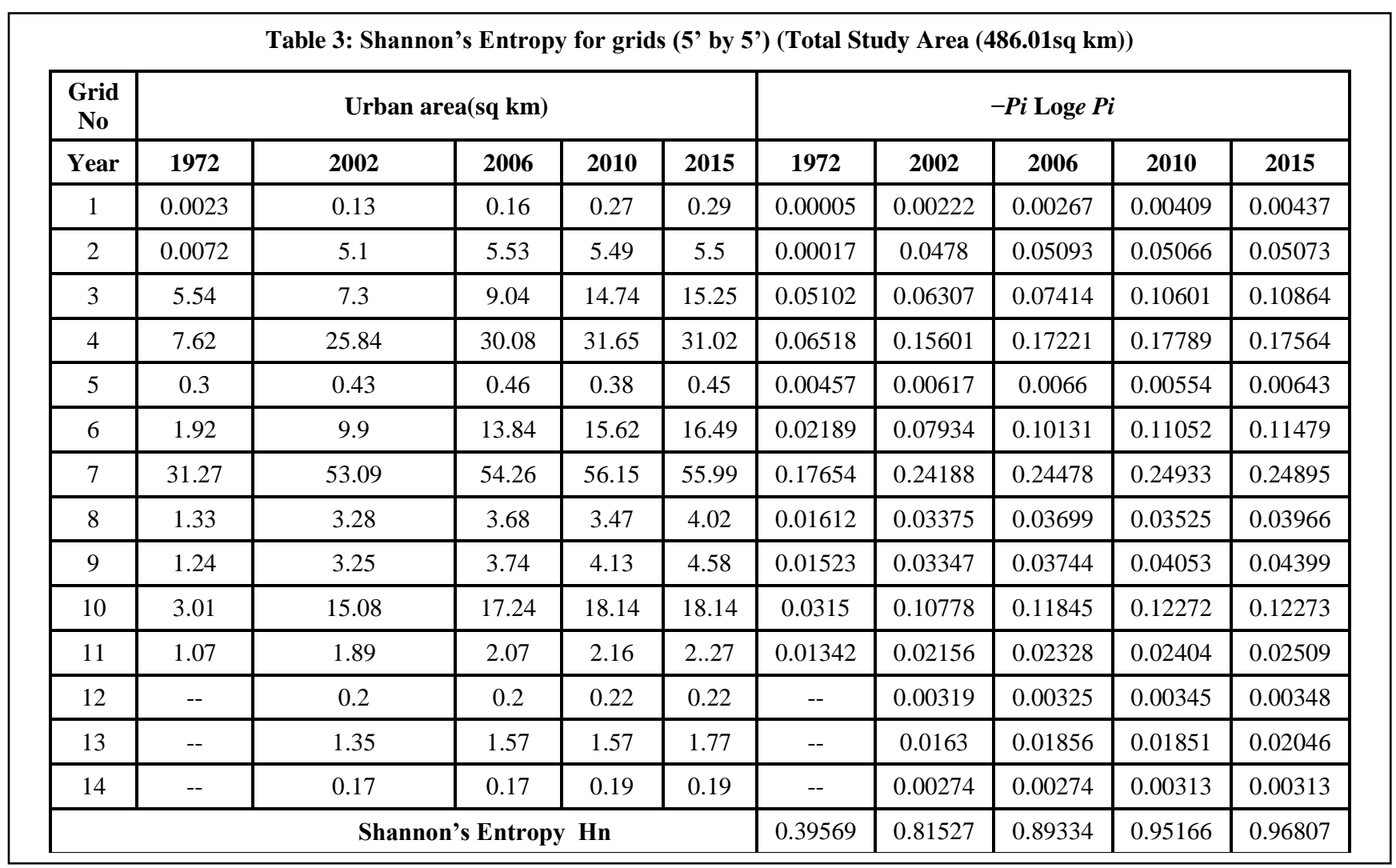

$$
\begin{aligned}
& \Delta H_{n}=H_{n}(2002)-H_{n}(1972)=0.82-0.40=0.42 \\
& \Delta H_{n}=H_{n}(2006)-H_{n}(2002)=0.90-0.82=0.08 \\
& \Delta H_{n}=H_{n}(2010)-H_{n}(2006)=0.95-0.90=0.06 \\
& \Delta H_{n}=H_{n}(2015)-H_{n}(2010)=0.97-0.95=0.02
\end{aligned}
$$

Table 4: The calculated change in entropy values

\begin{tabular}{|c|c|c|}
\hline Year & $\boldsymbol{H}_{\boldsymbol{n}}$ & $\Delta \boldsymbol{H}_{\boldsymbol{n}}$ \\
\hline $\mathbf{1 9 7 2}$ & 0.395687 & -- \\
\hline $\mathbf{2 0 0 2}$ & 0.8152727 & 0.419586 \\
\hline $\mathbf{2 0 0 6}$ & 0.8933389 & 0.078066 \\
\hline $\mathbf{2 0 1 0}$ & 0.9516553 & 0.058316 \\
\hline $\mathbf{2 0 1 5}$ & 0.9680682 & 0.016413 \\
\hline
\end{tabular}

The difference of entropy between two different periods of time indicates the change in the degree of dispersion of land development or urban sprawl (Sudhira et al. 2004). Results indicate that there was tremendous increase in urban areas from 1972-2002( $\Delta \mathrm{Hn}=0.42)$ and successively in 2002-2006 $(\Delta \mathrm{Hn}=0.08)$ and $2006-2010(\Delta \mathrm{Hn}=0.06)$ but is quite low in 2010-2015 ( $\Delta \mathrm{Hn}=0.02)$. The results showed that large urban sprawl was witnessed in earlier years but less new areas have been added up in 2010-2015 as compared to previous years.

\subsection{Creating a Sprawl Entropy Surface for different grids of Amritsar City}

Shannon Entropy interpolation methods have been used to create an entropy surface. This measure is based on the notion that disorganisation in the urban area increases with the increase in the landscape entropy values. Using ESRI Arc GIS 10.0 Spatial Analyst, the mean entropy value for each grid was assigned to its centroid (centre of polygon). Using these centre values in ArcGIS (ESRI product) software extension Spatial Analyst Tools, interpolation method has applied for Shannon's entropy values for all five sets of data time period (i.e. 1972, 2002, 2006, 2010 and 2015). Next, an interpolation function was run using the Inverse distance weighted tool (IDW). The Inverse Distance Weighted (IDW) is a method of interpolation that estimates cell values by averaging the values of sample data points in the neighborhood of each processing cell. The closer a point is to the center of the cell being estimated, the more influence, or weight; it has in the averaging process (ESRI ArcGIS 9.3, 2008). These steps were repeated for all five sets of entropy data calculated for the 14 grids in the five investigated years. A dispersed urban growth is revealed by the results of Shannon's entropy (Figure 1014). 


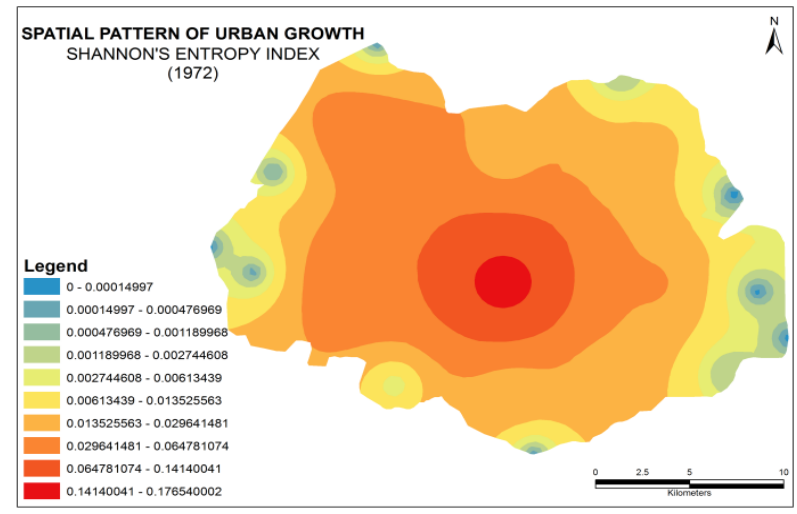

Fig 10: Shannon's Entropy (1972)

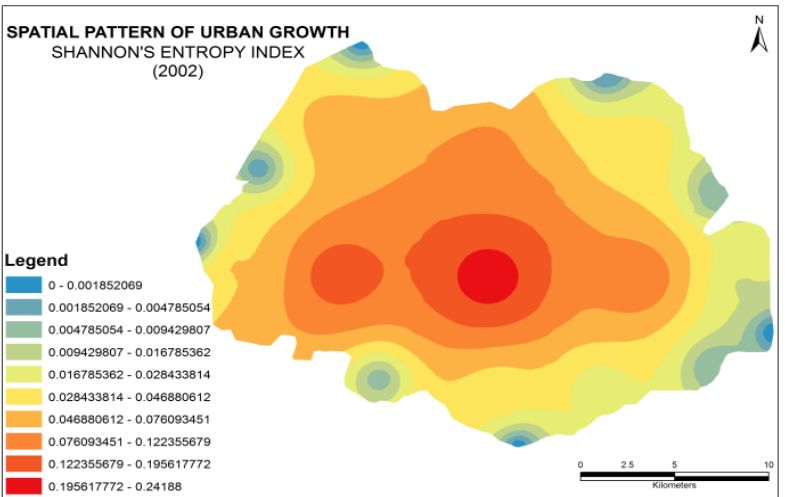

Fig 11: Shannon's Entropy (2002)

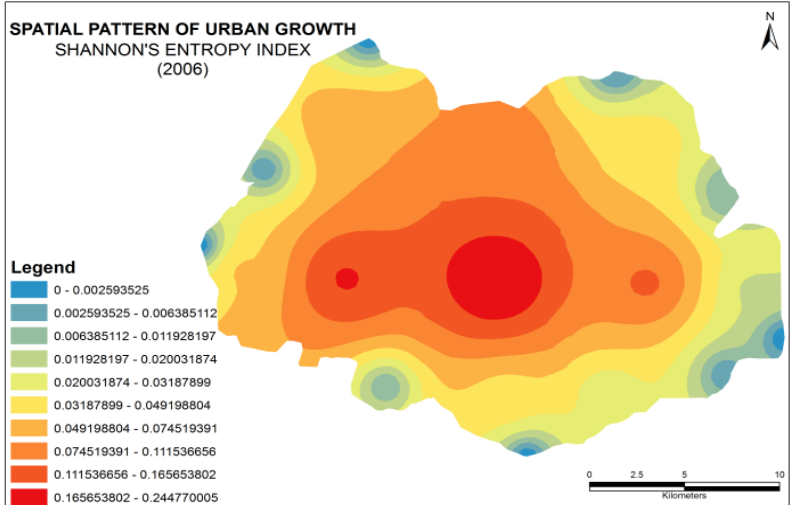

Fig 12: Shannon's Entropy (2006)

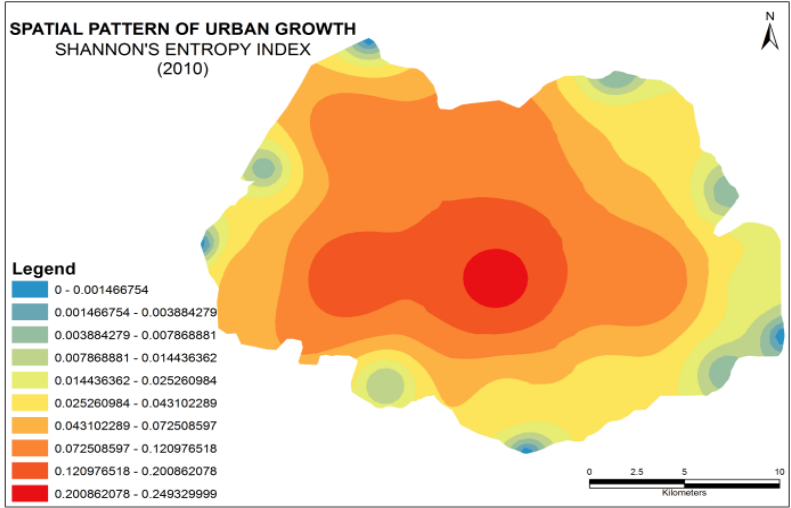

Fig 13: Shannon's Entropy (2010)

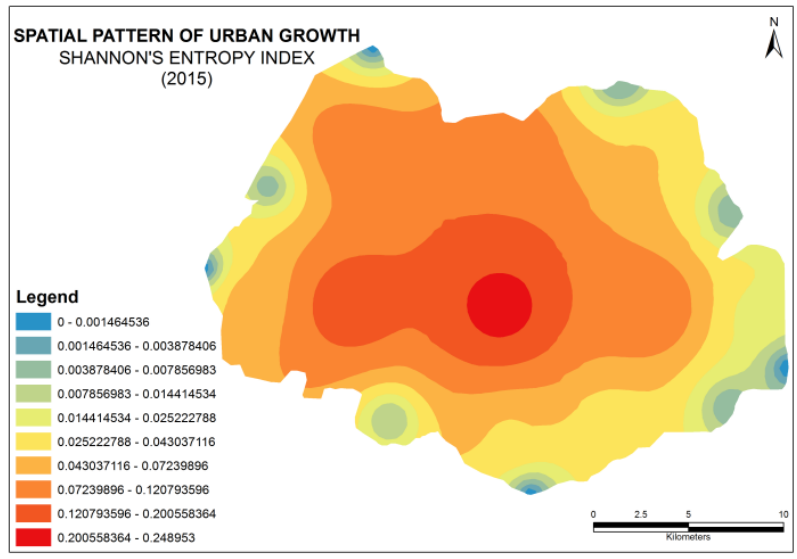

Fig 14: Shannon's Entropy (2015)

The entropy surface (index) is helpful for understanding the temporal and spatial changes in urban growth among the city. This tool can help decision makers in discussing and analyzing current and future trends and controls for future growth among the various grids of the city. The high entropy values indicate that there is an increase in urban sprawl. The index maps were classified into ten classes. Based on the entropy indices, the pattern of sprawl was examined. Amritsar City appears as old city in the centre of the study area characterized by high density buildings and entropy values increases gradually from the centre to west as well as eastern side along the national highway. In 2002 after a time gap of thirty years a large increase in entropy was observed in the western side which indicates the built up growth towards Cheherhta. This increase can be attributed due to the establishment of Guru Nanak Dev University and Polytechnic College. The trend of entropy increase continued in successive years and increase in entropy has been observed towards eastern side in 2006 due to urban sprawl. In 2010 and 2015 entropy increase in all the grids was observed.

\subsection{Increase in Population of Amritsar city (1971-2015)}

According to census 2015 the total population of Amritsar city has been upto1, 205,321 is much more than the total population of the city in 1971 (434951) (Table 5). There is increase of 2.77 times (177.1 percent) of population in forty five years. Population growth in Amritsar has been accompanied by an unprecedented wave of development which is supported by increase in tourism activities in the city. The Golden Temple is visited by people from far and wide in large number thus encouraging business and property developers in Amritsar to invest heavily. This further led to migration of people from various parts of state in search of employment and better standard of living.

Table 5: Urban population in Amritsar city during 19712001

\begin{tabular}{|c|c|c|}
\hline Year & Population & $\begin{array}{c}\text { per cent increase in } \\
\text { population from 1971 }\end{array}$ \\
\hline 1971 & $4,34,951$ & - \\
\hline 1981 & $5,94,844$ & 36.8 \\
\hline 1991 & $7,08,835$ & 62.9 \\
\hline
\end{tabular}




\begin{tabular}{|c|c|c|}
\hline 2001 & 966862 & 122.3 \\
\hline 2011 & $11,32,761$ & 160.4 \\
\hline 2015 & $12,05,321$ & 177.1 \\
\hline
\end{tabular}

It is evident from the study that the urban area has increased almost three times since 1972. It is been seen in the land use map for year 1972, 2002 and 2006 that the built up has been flourished on mainly on agriculture land. Hence the fertile crop land is being used in extensive amount though this consumption obviously includes all development initiatives for commercial, industrial, residential, educational and recreational establishments. While after 2002 the increase in urban area is moderate. During the last forty three years on an average 2.39 sq. $\mathrm{km}$ of area per year is paved over or otherwise converted to urban human uses. Notwithstanding the poor pollution control facilities, the enraging population consumes additional resources and creates additional waste. All this has resulted in decline in the quality of life, especially for the growing development one of the primary issues is the loss of prime agricultural land due to urbanization.

\subsection{Conclusion}

It is apparent from the study that the horizontal growth is very high than the population growth of the city. The city is located in the fertile agricultural land and as observed the agricultural land is being consumed at alarming rate for unplanned development of urban regions. Hence, the Amritsar city needs proper management to attain sustainable development. Urban fringe development of construction sites are easily delineated because of new generation of high resolution satellite imagery with 1 meter resolution in panchromatic mode their tone, texture and pattern with more accuracy. The method of Shannon's Entropy with the help of Geographic Information System (GIS) and The calculated Shannon's entropy for built up area of the study area confirms that the development is highly dispersed as the entropy for 2015 is 0.968 . The urban sprawl maps generated using GIS technologies are very useful for the town planners to formulate the proper development plans and to check the haphazard and uncontrolled urban growth. These maps can provide urban planners with a better understanding of city growth, dynamics of the urban-rural interface, monitoring of stress on the existing civic amenities and urban infrastructure. By monitoring changes in the urban sprawl over a period of time, the impact of changing land use on land, ecology and environment system can be assessed.

\section{REFERENCES}

[1] Yeh, A.G.O., and Li, X. Measurement and Monitoring of Urban Sprawl in a Rapidly Growing Region Using Entropy. Photogrammetric Engineering and Remote Sensing.2001, 67, 83-.

[2] Theobald, D.M. Quantifying Urban and Rural Sprawl Using the Sprawl Index. Proceedings of the Annual
Conference of the Association of American Geographers, New York, 2 March 2001

[3] Barnes, K.B., Morgan III, J.M., Roberge, M.C. and Lowe, S. Sprawl Development: Its Patterns, Consequences and Measurement. Towson University. 2001.

[4] Sudhira, H.S., Ramachandra, T.V., and Jagadish, K.S. Urban Sprawl: Metrics, Dynamics and Modelling Using GIS. International Journal of Applied Earth Observation \& Geoinformation. 2004. 5; 29.

[5] Wei, J., Ma, J., Twibell, R.W. and Underhill, K. Characterizing Urban Sprawl Using Multi-Stage Remote Sensing Images and Landscape Metrics. Computers, Environment and Urban Systems. 2006, 30, 861-897.

[6] Yu, X.J. and Ng, C.N. Spatial and Temporal Dynamics of Urban Sprawl along Two Urban-Rural Transects: A Case Study of Guangzhou, China. Landscape and Urban Planning. 2007, 79, 96-10.

[7] Jat, M.K., Garg, P.K., and Khare, D. Modeling of Urban Growth using Spatial Analysis Techniques: A Case Study of Ajmer City (India). International Journal of Remote Sensing. 2008. 29 (2) 543-567.

[8] Shekhar, S. Urban Sprawl Assessment Entropy Approach. GIS Development. 2004,8, 43-48.

[9] Punia, M., and Singh, L. Entropy Approach for Assessment of Urban Growth: A Case Study of Jaipur, India. Indian Society of Remote Sensing. 2012. 40 (2) 231-244.

[10] Singh, B. Urban Sprawl Using Shannon Entropy, a Case Study of Rohtak City. International Journal of Advanced Remote Sensing and GIS International, 2014, 3, 544-552

[11] Hala, A., Effat,M. and Shobaky,El. Modeling and Mapping of Urban Sprawl Pattern in Cairo

[12] ESRI (2008) Arc GIS, Release 9.3. Environmental Systems Research Institute, Redlands, CA.

[13] Using Multi-Temporal Landsat Images and Shannon's Entropy, Advances in Remote Senisng.2015, 4,303-318.

[14] Population Research Bureau, 2005: Human Population: Fundamental of Growth, Patterns of World Urbanisation. Population Reference Bureau, Inc., Washington, DC .

[15] Theobald, D.M. Quantifying Urban and Rural Sprawl Using the Sprawl Index. Proceedings of the Annual Conference of the Association of American Geographers, New York, 2 March 2001.

[16] United Nations, 2003: Worlds Urbanization Prospects. The 2003 Revision, New York. 